\title{
Author Correction: The future of Blue Carbon science
}

Peter I. Macreadie (D), Andrea Anton (D), John A. Raven, Nicola Beaumont, Rod M. Connolly (D), Daniel A. Friess, Jeffrey J. Kelleway (1D, Hilary Kennedy, Tomohiro Kuwae, Paul S. Lavery (D, Catherine E. Lovelock (D,

Dan A. Smale (1D, Eugenia T. Apostolaki (D), Trisha B. Atwood, Jeff Baldock (1), Thomas S. Bianchi, Gail L. Chmura (D), Bradley D. Eyre (D), James W. Fourqurean (D), Jason M. Hall-Spencer (D), Mark Huxham, Iris E. Hendriks (D, Dorte Krause-Jensen (1), Dan Laffoley (1), Tiziana Luisetti (D), Núria Marbà (1), Pere Masque (D), Karen J. McGlathery, J. Patrick Megonigal (D), Daniel Murdiyarso, Bayden D. Russell (1D, Rui Santos (D), Oscar Serrano (D), Brian R. Silliman, Kenta Watanabe \& Carlos M. Duarte (1)

Correction to: Nature Communications https://doi.org/10.1038/s41467-019-11693-w, published online 05 September 2019.

The original version of this Article contained an error in the author affiliations.

Affiliation 24 incorrectly read 'School of Applied Sciences, Edinburgh University, Edinburgh EH11 4BN, UK'

This has now been corrected in both the PDF and HTML versions of the Article.

Published online: 08 November 2019

\footnotetext{
(c) Open Access This article is licensed under a Creative Commons Attribution 4.0 International License, which permits use, sharing, adaptation, distribution and reproduction in any medium or format, as long as you give appropriate credit to the original author(s) and the source, provide a link to the Creative Commons license, and indicate if changes were made. The images or other third party material in this article are included in the article's Creative Commons license, unless indicated otherwise in a credit line to the material. If material is not included in the article's Creative Commons license and your intended use is not permitted by statutory regulation or exceeds the permitted use, you will need to obtain permission directly from the copyright holder. To view a copy of this license, visit http://creativecommons.org/licenses/by/4.0/.
}

(C) The Author(s) 2019 